\title{
Willingness to Pay for Cancer Genetic Testing in a Tertiary Healthcare Centre
}

\author{
Aizuddin $\mathrm{AN}^{\mathrm{a}}$, Syed Rusli $S A S^{\mathrm{a}}$, Ramdzan $A R^{\mathrm{a}, \mathrm{b}}$, Syed Omar $S A^{\mathrm{c}}$, Mahmud $Z^{\mathrm{c}}$, Abdul Latiff $Z^{\mathrm{d}}$, Shah $\mathrm{SA}^{\mathrm{a}}$, \\ Amat $S^{c}$, Ismail $F^{e}$, Keng $\mathbf{W T}^{f}$, Ch'ng GS $^{f}$, Rais $\mathbf{H}^{\mathrm{g}}$, Aljunid $\mathbf{S M}^{\mathrm{a}, \mathrm{h}}$ \\ ${ }^{a}$ Department of Community Health, Faculty of Medicine, National University of Malaysia, Jalan Yaacob Latif, Kuala Lumpur, Malaysia \\ ${ }^{b}$ Department of Community \& Family Medicine, Faculty of Medicine and Health Sciences, University of Malaysia Sabah, Sabah, Malaysia. \\ ${ }^{c}$ Faculty of Education, National University of Malaysia, Selangor, Malaysia. \\ ${ }^{d}$ Department of Paediatrics, Faculty of Medicine, National University of Malaysia, Kuala Lumpur, Malaysia \\ ${ }^{e}$ Department of Oncology \& Radiotherapy, Faculty of Medicine, National University of Malaysia, Kuala Lumpur, Malaysia \\ ${ }^{f}$ Genetic Department, Hospital Kuala Lumpur, Kuala Lumpur, Malaysia. \\ ${ }^{g}$ Department of Education Psychology \& Counseling, Kulliyyah of Education, International Islamic University Malaysia, Kuala Lumpur, Malaysia \\ ${ }^{h}$ Department of Health Policy and Management, Faculty of Public Health, Health Science Center, Kuwait University, Kuwait
}

\begin{abstract}
Keywords

Willingness to pay, Genetic testing, Cancer, Genetic

Corresponding Author

Associate Professor Dr. Azimatun Noor Aizuddin

Department of Community Health, Faculty of Medicine, National University of Malaysia, Jalan Yaacob Latif, Bandar Tun Razak, Cheras, 56000 Kuala Lumpur, Malaysia

Tel No: +60391458782/ +60193750153

Email: azimatunnoor@ppukm.ukm.edu.my

Received: 11 March 2020; Accepted: 17 March 2021

Doi: https://doi.org/10.31436/imjm.v20i3

INTRODUCTION: Increasing use of predictive genetic testing to address hereditary cancer risk has been commonly assessed by cost sharing practices. Little is known about how demographics, knowledge, attitude and practices may influence these individuals' willingness to pay for cancer genetic testing. The objective of this research was to determine factors associated with willingness to pay for cancer genetic testing. MATERIALS AND METHODS: A self-administered questionnaire was distributed to 175 respondents in the oncology and day care unit in one of tertiary healthcare centre. The respondents comprised cancer patients, their family members and the community. RESULTS: A total of $117(66.9 \%)$ participants were willing to pay for cancer genetic testing. Ninety three $(79.5 \%)$ of respondents were willing to pay from their own pocket with a mean of MYR1201.77 (SD976.72) and 95 (54.3\%) respondents were willing to pay, shared with insurance. There were significant associations between willingness to pay with status of respondent as patients or family members or community, gender, race, educational level, income, knowledge and attitude. CONCLUSION: This is the first study to evaluate factors associated with willingness to pay not only among cancer patients but also their family members and the community. These findings reveal that majority of respondents believe there is valuable personal benefit based on genetic risk information and they are willing to pay for it.
\end{abstract}

\section{INTRODUCTION}

Genetic test could reveal specific inherited changes, alterations or mutations in an individual's deoxyribonucleic acid (DNA), chromosomes or genes that may be harmful. A damage or mutation in the DNA could increase the chance or risk of developing diseases such as cancer. ${ }^{1}$ Genetic test could provide a better understanding on the risks of developing diseases, determine their health care and medical treatment plans as well as adjusting their lifestyles. The genetic testing specifically for cancer is mostly recommended for people with family history of inherited cancer risk conditions. $^{2}$ Cancer genetic testing involves a pretested consultation with a doctor, genetic counsellor or other health professionals. Genetic counselling is recommended prior and after the test to help the person manage their emotions and plan further effective actions. ${ }^{3}$

Willingness to pay (WTP) is a measure used in economic research to determine the successful rate of a programme or service. It represents an individual's capability in expending the maximum amount of money to equalize a utility change. ${ }^{4}$ The drawn WTP construct has been used as a method of assessing individuals view on health care interventions. However, there is a scarcity in research study that address an individual's WTP for genetic test for cancer predisposition and its associated factors. 
According to the International Agency for Research on Cancer, 43, 837 individuals out of 32.0 million populations in Malaysia, were diagnosed with cancer in 2018.5 Based on the database of National Cancer Society Malaysia, the most common types of cancers were breast, colorectal, lung, cervical and nasopharyngeal cancers. ${ }^{6}$ Despite the increasing number of cases in the country, cancer and genetic testing are not familiar among Malaysians, except for those in the medical profession. Yip et al. has reported that Malaysian women suffering from breast cancer have poor survival rate whereas an early diagnosis could have prevented half of the cancer-related mortality. ${ }^{7}$ Breast cancer awareness is poor amongst Malaysian women and very few women were likely to attend regular mammography screening. ${ }^{7}$ Besides, some of them also believe in cancer fatalism and alternative medicine and many have lack of autonomy in the decision making. This has also led to delay in seeking proper treatment and evidence-based medicine. Genetic testing for cancers shows that $15 \%$ of breast cancer patients were reported to have a family history of breast and ovarian cancers. ${ }^{8}$ A cross-sectional study involving 131 high-risk women with a family history of breast cancer showed that $71 \%$ women had poor knowledge regarding the risk factor of breast cancer. ${ }^{9}$ According to Yip et al., genetic counselling and genetic testing were accepted by $82 \%$ of women with high risk for hereditary breast and ovarian cancer syndromes. ${ }^{7}$ However, only $78 \%$ of the carriers had informtheir status to their respective families and merely $11 \%$ of the relatives had come forward to take the predictive testing although the genetic counselling and testing were free of charge. ${ }^{7}$ Previously, the genetic testing and risk management clinic at University Malaya Medical Centre (UMMC) had offered genetic screening for their high-risk breast and ovarian cancer families. Their recordshowed that only $63.5 \%$ of eligible women chose to attend this clinic whereas $24 \%$ chose to have risk-reducing mastectomy and the rest had chosen breast surveillance. For ovarian cancer, only $63 \%$ of the target chose to have the risk-reducing salpingooophorectomy. ${ }^{7}$

Most of the individuals does not have any positive family history of the cancer nor do they have any real perception on the disease. In such scenario, unsurprisingly there will be an unwillingness to pay for the genetic testing for cancer risk. Amongst the IMJM Volume 20 No.3, July 2021 pertinent questions that may arise include: How much would people be willing to self-pay for the service? How would various demographic characteristics or knowledge, attitude and practice have impact on the individuals' WTP? Their responses would be essential to the public health practitioners in planning interventions to guide the public to be well-informed and to make balanced decisions regarding on undertaking the genetic testing for cancer risk.

The main objective of this study was to determine factors associated with WTP for cancer genetic testing.

\section{MATERIALS AND METHODS}

This study was conducted at one of the tertiary health care centres from January until February, 2017. The target population comprised of all types of cancer patients and the immediate person who accompanied them to the oncology clinic and day-care unit. Universal sampling was used, and a total of 205 questionnaire was distributed. Those who did not provide consent and unfit to participate were excluded from the study.

The socio-demographic information included were gender, race, religion, marital status, number of children, educational status, monthly income and status of health insurance. Personal history of cancer was documented in addition to the record on family history of cancer amongst first-degree and the extended relatives. General knowledge on cancer was evaluated using eight items. The responses of 'Yes' and 'No' or 'Not-Sure' was scored as ' 1 ' or ' 0 ', respectively. The total score obtained was then classified into low (0-4), and high (5-8) level of knowledge. General knowledge of genetics and genetic testing was evaluated with ten items, respectively. It was scored 1 for 'Yes' and 0 for 'No' or 'Not Sure' response. The total score was classified into low (0-5), and high (610) level of knowledge. Attitude towards genetic testing was evaluated with thirteen items. It was scored on a 5Likert Scale: Not Related (0), Strongly Disagree (1), Disagree (2), Neutral (3), Agree (4) and Strongly Agree (5). The total score was classified into negative (0-32), and positive (33-65) attitude. Genetic testing practices for cancer predisposition were assessed with thirteen items if the respondents have undergone genetic testing. Information collected included source of information on genetic testing, source of referral pre and post-test for 
genetic counselling availability and the process of seeking informed consent. These were scored as ' 1 ' for Yes, '2' for No and ' 3 ' for Not Sure. Additionally, they were also asked for the location in which the genetic testing was undertaken. Besides, other questions were also included such as whether they shared their results with family members, do they cascade genetic testing amongst family members was performed, do they received emotional support from a genetic counsellor and family members, or whether they practiced healthy lifestyle. Generally, the WTP for cancer genetic testing was evaluated based on these seven items. Respondents were inquired on their WTP for cancer genetic testing and the amount of contribution if they were willing to do so. Data were analysed statistically using SPSS version 22 and $\mathrm{p}$-value of $<0.05$ were considered as statistically significant.

\section{RESULTS}

A total of 175 respondents completed the questionnaires, with the response rate being 87.5\%. Almost half of the respondents were cancer patients (86, 49.1\%). Eighty-five $(48.6 \%)$ respondents were between the age of 40 and 60 years old with a mean age of 49.29 years old (SD 15.16). Majority of the respondents were female $(135,77.1 \%)$, Malay (125, $71.4 \%$ ), Muslim $(127,72.6 \%)$ and married $(133,76.0 \%)$. Among the respondents, $87(49.7 \%)$ of them were university graduates. The respondents' income ranged from MYR 2000 - MYR 30000 with the mean income of MYR 3756.00 (SD 3672.21). Additionally, 78 (44.6\%) respondents earned less than MYR3000 and 63 (36.0\%) respondents earned between MYR3001 - MYR5000. Moreover, only $59(33.7 \%)$ respondents had private

Table 1 Factors Associated with Willingness to Pay (WTP) in General ( $n=175)$

\begin{tabular}{|c|c|c|c|c|}
\hline & $\begin{array}{l}\text { WTP } \\
\text { n (\%) }\end{array}$ & $\begin{array}{c}\text { Not WTP } \\
\text { n (\%) }\end{array}$ & $x^{2}$ & $p$-value \\
\hline \multicolumn{5}{|l|}{ Sociodemographic } \\
\hline Status of Respondent & & & 5.801 & 0.055 \\
\hline Patient & $50(58.1)$ & $36(41.9)$ & & \\
\hline Family & $43(75.4)$ & $14(24.6)$ & & \\
\hline Community & $24(75.0)$ & $8(25.0)$ & & \\
\hline Age & & & 7.708 & $* 0.021$ \\
\hline$<40$ & $35(77.8)$ & $10(22.2)$ & & \\
\hline $40-60$ & $59(69.4)$ & $26(30.6)$ & & \\
\hline$>60$ & $23(51.1)$ & $22(48.9)$ & & \\
\hline Gender & & & 1.552 & 0.213 \\
\hline Male & $30(75.0)$ & $10(25.0)$ & & \\
\hline Female & $87(64.4)$ & $48(35.6)$ & & \\
\hline Marital Status & & & 2.064 & 0.151 \\
\hline Unmarried & $22(78.6)$ & $6(21.4)$ & & \\
\hline Married & $95(64.6)$ & $52(35.4)$ & & \\
\hline Number of Children & & & 0.181 & 0.671 \\
\hline$<3$ & $79(65.8)$ & $41(34.2)$ & & \\
\hline$\geq 3$ & $38(69.1)$ & $17(30.9)$ & & \\
\hline Education Level & & & 9.977 & $* 0.002$ \\
\hline Low & $49(55.7)$ & $39(44.3)$ & & \\
\hline High & $68(78.2)$ & $19(21.8)$ & & \\
\hline Income & & & 6.770 & $* 0.009$ \\
\hline$<5000$ & $82(61.7)$ & $51(38.3)$ & & \\
\hline$\geq 5000$ & $35(83.3)$ & $7(16.7)$ & & \\
\hline Health Insurance & & & 1.458 & 0.227 \\
\hline Yes & $43(72.9)$ & $16(27.1)$ & & \\
\hline No & $74(63.8)$ & $42(36.2)$ & & \\
\hline Family History of Cancer & & & 4.821 & $* 0.028$ \\
\hline Yes & $48(58.5)$ & $34(41.5)$ & & \\
\hline No & $69(74.2)$ & $24(25.8)$ & & \\
\hline \multicolumn{5}{|l|}{ Knowledge on Cancer } \\
\hline Low Knowledge & $11(42.3)$ & $15(57.7)$ & & \\
\hline High Knowledge & $106(71.1)$ & $43(28.9)$ & & \\
\hline Genetic & & & 8.150 & $* 0.004$ \\
\hline Low Knowledge & $42(55.3)$ & $34(44.7)$ & & \\
\hline High Knowledge & $75(75.8)$ & $24(24.2)$ & & \\
\hline Genetic Testing & & & 5.919 & $* 0.015$ \\
\hline Low Knowledge & $58(59.2)$ & $40(40.8)$ & & \\
\hline High Knowledge & $59(76.6)$ & $18(23.4)$ & & \\
\hline Attitude & & & 4.812 & $* 0.028$ \\
\hline Negative Attitude & $3(33.3)$ & $6(66.7)$ & & \\
\hline Positive Attitude & $114(68.7)$ & $52(31.3)$ & & \\
\hline Practice & & & 1.612 & 0.204 \\
\hline Yes & $7(87.5)$ & $1(12.5)$ & & \\
\hline No & $110(65.9)$ & $57(34.1)$ & & \\
\hline
\end{tabular}


health insurance while ninety-three (53.1\%) respondents had family history of cancer. Potential demographic and psychosocial predictors of WTP for cancer genetic testing were as shown in Table 1.

In general, 117 respondents $(66.9 \%)$ reported that they were WTP for cancer genetic testing (Table 1). Among these, 93 respondents $(79.5 \%)$ were willing to self-pay with a mean of MYR1201.77 (SD 976.72) and 95 respondents $(54.3 \%)$ were WTP if the total cost was shared with the insurance provider. One hundred and thirty-eight respondents (78.9\%) were WTP for cancer genetic testing if they were given full coverage from the insurance and 146 respondents (83.4\%) were WTP if it was fully covered by the government.

The results showed that there were $85.1 \%$ respondents with high knowledge on cancer with a mean score of 5.29 (SD 1.51) and cancer patients (69) being the majority of the respondents. Furthermore, 41 (41.4\%) patients had high knowledge on genetics followed by 39 (39.4\%) family members, and 19 (19.2\%) community members. Only $77(44.0 \%)$ respondents had high knowledge on genetic testing with a mean score of 4.73 (SD 2.95 with patients being the highest in the list $(50.6 \%)$ followed by family members (33.8\%), and community members $(15.6 \%)$. One hundred and sixtysix $(94.9 \%)$ respondents showed positive attitude towards cancer genetic testing in which majority of the respondents were patients $(48.2 \%)$, followed by family members (33.1\%), and community members (18.7\%). Nonetheless, only 8 respondents $(4.6 \%)$ underwent cancer genetic testing in which 3 of them were patients and another five were family members.

Overall, there was significant association between WTP and age $(p=0.021)$, educational level $(p=0.002)$, income $(p=0.009)$ and family history of cancer $(p=0.028)$. The WTP was higher among respondents aged less than 40 years old, highly educated, with monthly income of less than MYR5000 and without family history of cancer (Table 1). Furthermore, the present study showed that there were significant associations between W'TP and knowledge on cancer $(p=0.004)$, genetics $(p=0.004)$, as well as genetic testing $(p=0.015)$. The percentage of respondents who were WTP was higher among respondents with high knowledge compared to the respondents who had lower knowledge. There were a significant association between the WTP and attitude $(p=0.028)$ in which the percentage of individual's WTP was higher among individuals with positive attitude. Notably, the percentage of individual's WTP was higher among those who practiced genetic testing, but the association was not significant $(p=0.204)$.

In specifically among patients, the WTP were also assessed based on the same factors. Table 2 shows significant association between WTP and income $(p=0.024)$. Cancer patients with income more than MYR5000 shows a higher percentage of WTP compared to patients with income less than MYR5000. Furthermore, there were also significant associations between WTP and knowledge on cancer $(p=0.007)$, on genetics $(p=0.007)$ and on genetic testing $(p=0.019)$. The percentage of WTP was higher among patients with high knowledge compared to the patients with lower knowledge. There was also significant association between WTP and attitude $(p=0.033)$, in which the percentage of W'TP was higher among patients with positive attitude. However, there was no significant association between WTP and practice of cancer genetic testing.

From the total number of respondents, 57 of them were family members and 32 of the respondents were from the community. None of the socio-demographic, knowledge, attitude or practice factors were found to have significant association with the WTP for cancer genetic testing among family members and community members.

Based on the results obtained from the bivariate analysis above, all factors with $p<0.25$ were selected and further proceed with the multivariate analysis in general, among patients, family members and community as stated by Bursac et al. 10 Table 3 shows the determinant factors influencing the WTP for cancer genetic testing based on the Multiple logistic regression analysis. The analysis shows that only knowledge for genetic testing was found to be significant for WTP for cancer genetic testing in general $(p=0.004)$ and among patients $(p=0.013)$. However, knowledge for genetic testing was found not to be significant with WTP for cancer genetic testing among family members and community. The Nagelkerke's $\mathrm{R}^{2}$ calculated was 0.255 and 0.293 respectively. The remaining $74.5 \%$ and $70.7 \%$ may be 
Table 2 Factors Associated with Willingness to Pay (WTP) among Patient $(\mathrm{n}=86)$

\begin{tabular}{|c|c|c|c|c|}
\hline & WTP n (\%) & $\begin{array}{c}\mathrm{Not}_{(\%)}^{\text {WTP n }} \\
\text { N }\end{array}$ & $x^{2}$ & $\begin{array}{c}p- \\
\text { value }\end{array}$ \\
\hline \multicolumn{5}{|l|}{ Sociodemographic } \\
\hline Age & & & 4.255 & 0.119 \\
\hline$<40$ & $3(50)$ & $3(50)$ & & \\
\hline $40-60$ & $32(68.1)$ & $15(31.9)$ & & \\
\hline$>60$ & $15(45.5)$ & $18(54.5)$ & & \\
\hline Gender & & & 1.042 & $0.394^{\#}$ \\
\hline Male & $4(80.0)$ & $1(20.0)$ & & \\
\hline Female & $46(56.8)$ & $43(43.2)$ & & \\
\hline Marital Status & & & 0.786 & $0.569^{\#}$ \\
\hline Unmarried & $1(33.3)$ & $2(66.7)$ & & \\
\hline Married & $49(59.0)$ & $34(41.0)$ & & \\
\hline $\begin{array}{l}\text { Number of } \\
\text { Children }\end{array}$ & & & 3.013 & 0.083 \\
\hline $\begin{array}{l}<3 \\
\geq 3\end{array}$ & $\begin{array}{l}30(51.7) \\
20(71.4)\end{array}$ & $\begin{array}{c}28(48.3) \\
8(28.6)\end{array}$ & & \\
\hline Education Level & & & 3.278 & 0.070 \\
\hline Low & $28(50.9)$ & $27(49.1)$ & & \\
\hline High & $22(71.0)$ & $9(29.0)$ & & \\
\hline Income & & & 5.117 & $* 0.024$ \\
\hline$<5000$ & $34(51.5)$ & $32(48.5)$ & & \\
\hline$\geq 5000$ & $16(80.0)$ & $4(20.0)$ & & \\
\hline Health Insurance & & & 0.011 & 0.915 \\
\hline Yes & $12(57.1)$ & $9(42.9)$ & & \\
\hline No & $38(58.5)$ & $27(41.5)$ & & \\
\hline $\begin{array}{l}\text { Family History of } \\
\text { Cancer }\end{array}$ & & & 1.376 & 0.241 \\
\hline Yes & $20(66.7)$ & $10(33.3)$ & & \\
\hline No & $30(53.6)$ & $26(46.4)$ & & \\
\hline \multicolumn{5}{|l|}{ Knowledge on } \\
\hline Cancer & & & 7.185 & $* 0.007$ \\
\hline Low Knowledge & $5(29.4)$ & $12(70.6)$ & & \\
\hline High Knowledge & $45(65.2)$ & $24(34.8)$ & & \\
\hline Genetic & & & 7.274 & $* 0.007$ \\
\hline Low Knowledge & $20(44.4)$ & $25(55.6)$ & & \\
\hline High Knowledge & $30(73.2)$ & $11(26.8)$ & & \\
\hline Genetic Testing & & & 5.468 & $* 0.019$ \\
\hline Low Knowledge & $22(46.8)$ & $25(53.2)$ & & \\
\hline High Knowledge & $28(71.8)$ & $11(28.2)$ & & \\
\hline Attitude & & & 4.558 & $* 0.033$ \\
\hline Negative Attitude & $1(16.7)$ & $5(83.3)$ & & \\
\hline Positive Attitude & $49(61.2)$ & $31(38.8)$ & & \\
\hline Practice & & & 0.093 & $1.000^{\#}$ \\
\hline Yes & $2(66.7)$ & $1(33.3)$ & & \\
\hline No & $48(57.8)$ & $35(42.2)$ & & \\
\hline
\end{tabular}

*significant level at $p<0.05$

\#Fisher's Exact Test

contributed by other factors not included in the current study. Assumptions were also checked by assessing the goodness of fit of the model using the HosmerLemeshow test with $p=0.610$ and $p=0.385$, and a classification table reporting the overall percentages of correctly classified were at $66.1 \%$ and $72.1 \%$ respectively.

From the total number of respondents, 57 of them were family members and 32 of the respondents were from the community. None of the socio-demographic, knowledge, attitude or practice factors were found to have significant association with the WTP for cancer genetic testing among family members and community members.

Based on the results obtained from the bivariate analysis above, all factors with $p<0.25$ were selected and further proceed with the multivariate analysis in general, among patients, family members and community as stated by Bursac et al. 10 Table 3 shows the determinant factors influencing the WTP for cancer genetic testing based on the Multiple logistic regression analysis. The analysis shows that only knowledge for genetic testing was found to be significant for WTP for cancer genetic testing in general $(p=0.004)$ and among patients $(p=0.013)$. However, knowledge for genetic testing was found not to be significant with WTP for cancer genetic testing among family members and community. The Nagelkerke's $R^{2}$ calculated was 0.255 and 0.293

Table 3 Factors Associated with WTP in General, among Patients, Family Members and Community using Multivariate Logistic Regression Analysis

\begin{tabular}{llllll}
\hline Variable & $\begin{array}{l}\text { Regression } \\
\text { coefficient } \\
\mathbf{( b )}\end{array}$ & $\begin{array}{l}\text { Std } \\
\text { error }\end{array}$ & $\begin{array}{l}\text { Wald } \\
\mathbf{( z )}\end{array}$ & $\begin{array}{l}\text { Adjusted } \\
\text { odds } \\
\text { ratio } \\
\mathbf{( 9 5 \%} \mathbf{C I})\end{array}$ & $\begin{array}{l}\text { p- } \\
\text { value }\end{array}$ \\
\hline General & & & & & \\
$\begin{array}{l}\text { Knowledge } \\
\text { on Genetic }\end{array}$ & 1.072 & 0.372 & 8.313 & $1.409-$ & $\mathbf{0 . 0 0 4}$ \\
$\begin{array}{l}\text { Testing } \\
\text { Constant }\end{array}$ & -3.461 & 2.982 & 1.348 & & \\
$\begin{array}{l}\text { Patients } \\
\text { Knowledge } \\
\text { on Genetic }\end{array}$ & -1.255 & 0.507 & 6.129 & $0.106-$ & $\mathbf{0 . 0 1 3}$ \\
Testing & & & & 0.770 & \\
Constant & -10.317 & 3.713 & 7.719 & & 0.005 \\
\hline
\end{tabular}

respectively. The remaining $74.5 \%$ and $70.7 \%$ may be contributed by other factors not included in the current study. Assumptions were also checked by assessing the goodness of fit of the model using the HosmerLemeshow test with $p=0.610$ and $p=0.385$, and a classification table reporting the overall percentages of correctly classified were at $66.1 \%$ and $72.1 \%$ respectively.

\section{DISCUSSION}

The increasing availability of cancer genetic testing suggests that genetics development will slowly permeate into clinical practices beyond providing the traditional genetic services. ${ }^{11}$ An increasing number of people using genetic services may be associated with their exposure to the current advancement in cancer genetics which impacts various decision-making 
processes. The efficiency in utilising this advancement and making decision regarding the genetic risks will be depending on the individual's knowledge and attitude towards human genetics and its development. ${ }^{11}$

Majority of the respondents in this study were WTP for cancer genetic testing. This attitude was similar to the previous study on WTP but for inherited retinal disease in which majority of the participants were willing to undertake the genetic testing. ${ }^{12}$ Our study population was largely composed of middle-aged group in which majority of them were unemployed, had no source of income or was not aware of the cost of cancer genetic testing. Interestingly, more than half of the respondents were WTP for the test due to their heightened awareness that managing cancer is physically, mentally and financially challenging. Thus, more respondents were W'TP for cancer genetic testing to know their risk level of having cancer.

Previous study by Henneman et al. has reported that knowledge on cancer genetics and genetic testing as well as their attitude towards these were high among the study's respondents. ${ }^{13}$ This supports our current finding showing more respondents were knowledgeable regarding this and has positive attitude towards the use of genetic test. ${ }^{13}$ However, the practice of genetic testing is scarce especially in Malaysia due to little exposure and awareness towards such test compared to other developed countries. ${ }^{14}$

In general, family members should have higher WTP for genetic testing among the three categories of respondents. There were mixed findings from other studies regarding this. A review on the role of cancer worry in cancer screening behaviours found that majority of the people ranging from the high-risk to general population samples were not concerned about cancer. ${ }^{15}$ A negative relationship between cancer worry and screening was also observed as cancer worry was generally defined as fear about positive test result rather than worrying about the chances of developing cancer. Their worry also include carrying a retrospective attitude rather than being optimistic about the outcome. Nevertheless, when cancer worry is defined and measured as general worries about cancer, it is commonly related to the increased utilization of genetic screening tests. ${ }^{15} \mathrm{~A}$ study on the factors influencing an individual's WTP for BRCA1/2 genetic testing found that the subjects WTP was positively correlated with their numeracy and perceived risk. ${ }^{16}$

Current findings on the significant positive association between WTP and factors on knowledge was further supported by a previous study showing significant association between higher education levels with higher WTP. ${ }^{17}$ This could be due to individuals with higher education who were more keen to inquire about the genetic testing thus gaining better knowledge on the genetic testing. There was also an association between the respondents' income with WTP for cancer genetic testing. Our results on association between the WTP and respondents' income were similar to Tubeuf et al., who did a study on WTP for inherited retinal disease genetic testing. ${ }^{18}$ Besides, other studies have also reported a positive association between income and WTP for varied types of genetic testing. 19,20,21,22

The significant association between WTP and knowledge on cancer, genetics and genetic testing among cancer patients is not surprising. They were more prepared to receive more information regarding the cancer as well as about both the cancer genetics and genetic testing. This is similar to the finding reported by Sinead et al. on WTP for pharmacogenomics testing, in which the WTP was higher among patients who had better understanding on genetic testing. ${ }^{23}$ Interestingly, attitude was significantly associated with W'TP in current study. Jennifer et al. found that individuals with more positive attitudes towards genetic testing and cancer screening were more WTP for these services. ${ }^{24}$

This study was a pilot study which involved a small sample size that were recruited from a single institution. Future study involving larger sample size and recruitments from a multi-centric setting could provide more robust findings and supports current findings.

\section{CONCLUSION}

This pioneering study in Malaysia had addressed the WTP for cancer genetic testing based on the knowledge, attitude, and practice amongst not only cancer patients, but also among family members of cancer patients and 
the overall community. Current findings could provide overview on new perspectives and expectations from individuals other than the cancer patients on W'TP.

\section{CONFLICT OF INTEREST}

None of the authors have any conflicts of interest to declare.

\section{ACKNOWLEDGEMENT}

The authors would like to thank all the enumerators and staffs from oncology clinic for their cooperation during this study. The authors would also like to thank the Oxford Language Centre for their English writing support.

\section{FUNDING}

This study was part of the Long-Term Research Grant Scheme; The Cancer Genome Atlas (TCGA): Molecular Networks for Improving Diagnosis and Treatment of Cancer (sub-group 4 entitled Knowledge, Attitude, Practices (KAP), Cost-Benefit and Psycho-Education of Cancer Genetic Testing Among Patients, Family and Community). This study has obtained ethical approval from UKM Medical Ethics Committee.

\section{REFERENCES}

1. National Cancer Institute. Genetic testing for hereditary cancer syndromes. 2013. http:// www.cancer.gov/about-cancer/causes-prevention/ genetics/genetic-testing-fact-sheet\#q1. Accessed 10 March 2018.

2. American Cancer Society. Genetic testing for cancer: what you need to know. 2013. http:/ / www.cancer.org/acs/groups/cid/documents/ webcontent/002548-pdf.pdf. Accessed 10 March 2018.

3. American Cancer Society. What happens during genetic testing. http://www. cancer.org/cancer/ cancercauses/geneticsandcancer/genetictesting/ genetic-testing test-process. 2015. Accessed 10 March 2018.

4. Kopits IM, Chen C, Roberts JS, Uhlmann WR, Green RC. Willingness to pay for genetic testing for Alzheimer's disease: A measure of personal utility. Genetic Testing and Molecular Biomarkers. 2011; 15(12):871-875.

5. International Agency for Research on Cancer. Globocan 2018: Estimated cancer incidence, mortality, and prevalence worldwide in 2018. 2018. http://globocan.iarc.fr/Pages/ fact_sheets_cancer.aspx. Accessed 03 July 2020.

6. National Cancer Institute. Malaysian National Cancer Registry Report 2007-2011. 2016. http:/ / nci.moh.gov.my. Accessed 10 March 2018.

7. Yip CH, Pathy NB, Teo SH. A review of breast cancer research in Malaysia. The Medical Journal of Malaysia. 2014; 69: 8-22.

8. Kang PCE, Phuah SY, Sivanandan K, Kang IN, Thirthagiri E, Liu JJ, et al. Recurrent mutation testing of BRCA1 and BRCA2 in Asian breast cancer patients identify carriers in those with presumed low risk by family history. Breast Cancer Research \& Treatment. 2014; 144: 635-642.

9. Subramanian P, Oranye NO, Azimah MM, Nur Aishah T, Nora A. Breast cancer knowledge and screening behavior among women with a positive family history: a cross-sectional study. Asian Pacific Journal of Cancer Prevention. 2013; 14:6783-6790.

10. Bursac Z, Gauss CH, Williams DK, Hosmer DW. Purposeful selection of variables in logistic regression. Source Code for Biology and Medicine. 2008; 3:17.

11. Morren M, Rijken M, Baanders AN, Bensing J. Perceived genetic knowledge, attitudes towards genetic testing, and the relationship between these among patients with a chronic disease. Patient Education and Counseling. 2007; 65:197-204.

12. Sandy T, Thomas AW, Barbara P, Hilary G, Matthew JA, Mushtaq A, et al. Willingness to pay for genetic testing for inherited retinal disease. European Journal of Human Genetics. 2015; 23: 285-291.

13. Henneman L, Vermeulen E, van El CG, Claassen L, Timmermans DR, Cornel MC. Public attitudes towards genetic testing revisited: comparing opinions between 2002 and 2010. European Journal of Human Genetics. 2013; 21(8):793-799.

14. Balasopoulou A, Mooy FM, Baker DJ, Mitropoulou C, Skoufas E, Bulgiba A, Katsila T, Patrinos GP. Advancing Global Precision Medicine: An Overview of Genomic Testing and 
Counseling Services in Malaysia. A Journal of

Integrative Biology. 2017:21(12). https://

umexpert.um.edu.my/file/

publication/00000843_155723_67193.pdf.

Accessed 31 May 2019.

15. Hay JL, Buckley TR, Ostroff JS. The role of cancer worry in cancer screening: A theoretical and empirical review of the literature. PsychoOncology. 2005; 14:517-534.

16. Miron-Shatz T, Hanoch Y, Doniger GM, Omer ZB, Ozanne EM. Subjective but not objective numeracy influences willingness to pay for BRCA1/2 genetic testing. Judgment and DecisionMaking Journal. 2014; 9(2):152-158.

17. Frew E, Wolstenholme JL, Whynes DK. Willingness-to-pay for colorectal cancer screening. European Journal of Cancer. 2001; 37(14):1746-51.

18. Tubeuf S, Willis TA, Potrata B, Grant H, Allsop MJ, Ahmed M, et al. Willingness to pay for genetic testing for inherited retinal disease. European Journal of Human Genetics. 2015; 23:285-291.

19. Aizuddin AN, Aljunid SM. Systematic review of factors associated with willingness to pay for health financing scheme. Malaysian Journal of Public Health Medicine. 2017; 17(2): 103-112.

20. Aizuddin AN, Aljunid SM. Willingness to pay for outpatient services user fees: Malaysian community perspective. Jurnal Sains Kesihatan Malaysia. 2018; 16(1): 145-153.

21. Wan Puteh SE, Ahmad SNA, Aizuddin AN, Zainal R, Ismail R. Patients' willingness to pay for their drugs in primary care clinics in an urbanized setting in Malaysia: A guide on drug charges implementation. Asia Pacific Family Medicine. 2017; 16:5.

22. Ahmad SNA, Wan Puteh SE, Aizuddin AN.

Willingness to pay for drugs in future National Health Financing Scheme among Malaysian population. World Applied Sciences Journal. 2014; 30(3): 271-278.

23. Cuffe S, Hon H, Qiu X, Tobros K, Wong CK, De Souza B, et al. Cancer patients' acceptance, understanding, and willingness-to-pay for pharmacogenomic testing. Pharmacogenetics and Genomics. 2014; 24:348-355.

24. Matro JM, Ruth KJ, Wong YN, McCully KC, Rybak CM, Meropol NJ, et al. Cost sharing and hereditary cancer risk: Predictors of willingness-topay for genetic testing. Journal of Genetic Counseling. 2014; 23(6):1002-1011. 